\title{
Infectious gastro-enteritis: an uncommon cause of diarrhoea in adult allogeneic and autologous stem cell transplant recipients
}

\author{
MGJ van Kraaij ${ }^{1}$, AW Dekker ${ }^{1}$, LF Verdonck ${ }^{1}$, AM van Loon $^{2}$, J Vinjé ${ }^{3}$, MPG Koopmans ${ }^{3}$ and \\ M Rozenberg-Arska \\ ${ }^{1}$ Department of Haematology, ${ }^{2}$ Eijkman-Winkler Institute of Microbiology, Infectious Disease and Inflammation, University Medical \\ Centre Utrecht; and ${ }^{3}$ National Institute of Public Health and The Environment, Bilthoven, The Netherlands
}

\section{Summary:}

The incidence and aetiology of acute diarrhoea in 60 adult allogeneic or autologous stem cell transplant (SCT) recipients was determined in a prospective study. Stool specimens were obtained prior to SCT and on days $+\mathbf{2 0},+40,+60$ and $+\mathbf{1 0 0}$ post transplant. Microbiological evaluation was performed for pathogenic bacteria, fungi, parasites and viruses. Forty-seven patients were evaluable of whom 31 had a total of 48 acute diarrhoeal episodes. Diarrhoea occurred in $79 \%$ of allogeneic and $47 \%$ of autologous SCT recipients $(P<0.05)$. Intestinal infections were found in three of $48(6 \%)$ diarrhoeal episodes. Clostridium difficile with positive toxin was cultured twice and one stool specimen was positive for cryptosporidium. Intestinal pathogens were identified in 13 out of 172 stool specimens from asymptomatic patients and included: rotavirus (4), adenovirus (3), $C$. difficile, toxin positive (2), and others (4). Graft-versus-host disease was confirmed by biopsy in two of 36 episodes of diarrhoea in allogeneic patients, and in three patients a relationship between reactivation of cytomegalovirus and diarrhoea was suspected. In 40 of $48(83 \%)$ episodes of diarrhoea no clear aetiology could be found. Bone Marrow Transplantation (2000) 26, 299-303.

Keywords: gastro-enteritis; diarrhoea; infection; stem cell transplantation

Patients undergoing stem cell transplantation (SCT) are at high risk of bacterial, fungal and viral infections. Diarrhoea in stem cell transplant recipients is a frequent complication during the first 3 months after transplantation. The aetiology of diarrhoea in these patients is often difficult to ascertain. In the early phase of SCT, non-infectious events such as conditioning therapy and acute graft-versus-host disease (GVHD) may be implicated. Thereafter, infectious events, such as bacterial and viral gastro-enteritis may be a more frequent cause of diarrhoea in SCT recipients. Previous studies reported $C$. difficile as the most common bac-

Correspondence: AW Dekker, Department of Haematology, University Medical Centre Utrecht, Post Office Box 85500, 3508 GA Utrecht, The Netherlands

Received 16 November 1999; accepted 16 April 2000 terial cause of diarrhoea in SCT populations. ${ }^{1-3}$ In cases of viral gastrointestinal infection rotavirus, adenovirus, astrovirus and small round-structured virus (SRSV) have been identified as pathogens in patients undergoing stem cell transplantation besides herpes viruses such as cytomegalovirus. ${ }^{1,2,4-7}$ The incidence of infectious gastro-enteritis associated with allogeneic and autologous SCT reported in the literature varies from $13 \%$ to $40 \%$. $^{1,2,5}$ One study showed that $20 \%$ of SCT recipients developed viral gastro-enteritis. ${ }^{5}$ However, another prospective trial reported that only $13 \%$ of stem cell recipients developed a viral or bacterial intestinal infection. $^{2}$ Therefore, to determine the incidence and cause of acute diarrhoea in adult allogeneic and autologous SCT recipients in our hospital, we performed a prospective study.

\section{Patients and methods}

\section{Study population}

We prospectively studied 60 adult patients undergoing allogeneic and autologous SCT, who were hospitalised in the haematological ward of the University Medical Centre, Utrecht, The Netherlands, from June 1995 until June 1996. All patients received conditioning therapy with intensive cytotoxic chemotherapy with or without total body irradiation. Allogeneic SCT recipients received T celldepleted donor marrow, and cyclosporin A for GVHD prevention. Patients were nursed in a single room with free entry for staff and visitors. During profound neutropenic periods (granulocytes $<500 / \mu \mathrm{l}$ ) patients received oral prophylaxis with ciprofloxacin $500 \mathrm{mg}$ twice a day, amphotericin B $200 \mathrm{mg}$ four times a day and fluconazole $50 \mathrm{mg}$ once daily. For prevention of bacteraemias caused by $\alpha$ haemolytic streptococci patients received cephalotin $1000 \mathrm{mg}$ i.v. six times daily for 10 days after SCT. Prophylaxis with oral acyclovir $200 \mathrm{mg}$ four times a day was routinely used in patients undergoing allogeneic SCT during the first 12 months for prevention of herpes virus infections. In addition, patients who had a positive cytomegalovirus immediate-early antigen test (IEA-CMV) during the first 3 months after allogeneic SCT received pre-emptive therapy with ganciclovir, as described before. ${ }^{8}$ In addition to the antimicrobial prophylactic regimen, careful handwashing and use of low microbial food were standard infection preventive measures. 


\section{Study design}

Stool specimens were obtained from all SCT recipients prior to transplantation and on days $+20,+40,+60$ and +100 after transplantation. At least four surveillance cultures had to be obtained from a patient regarding evaluability. In addition, stool specimens were obtained at the onset of diarrhoea and twice weekly for 2 weeks thereafter. Diarrhoea was defined as an abnormal increase in stool liquidity and more than three bowel movements per day. During diarrhoeal episodes the following data were recorded: stool frequency and if possible stool volume (only during hospitalization), duration of diarrhoea, fever, nausea, vomiting, and abdominal pain. Diarrhoea was defined as infectious in cases of recovery from a known enteric pathogen, C. difficile and simultaneous detection of toxin, enteric virus (rotavirus, adenovirus, enteroviruses, SRSV, astrovirus), cytomegalovirus, or intestinal parasites. GVHD was diagnosed according to established criteria. ${ }^{9}$

\section{Microbiological evaluation}

Stool specimens were cultured for the presence of pathogenic bacteria such as Salmonella, Shigella, Campylobacter, Yersinia, $C$. difficile and yeast. $C$. difficile toxin was determined in stools by cytotoxic effects on Hela cells. All stool specimens were investigated for the presence of cryptosporidium by acid-fast stains and other parasites by standard laboratory methods. Viral diagnoses were performed by culture (enteroviruses and adenovirus). In addition, enzyme immunoassays were used to determine the presence of rotavirus and adenovirus, as described before. ${ }^{10}$ The presence of SRSV and astrovirus in stool specimens was investigated at the department of Virology, National Institute of Public Health and the Environment (RIVM) by use of reverse transcriptase PCR as described previously. ${ }^{11,12}$ If a patient had a positive cytomegalovirus immediate-early antigen test in combination with diarrhoea, diagnosis of the diarrhoea to be caused by cytomegalovirus was confirmed by endoscopy with biopsies according to the treating physician.

\section{Results}

Sixty SCT recipients were included in the study; 47 SCT recipients were considered evaluable. Reasons for exclusion were: lost to follow-up because of post-transplantation care in another hospital $(n=4)$, inability to obtain at least four surveillance cultures of faeces $(n=5)$, patient refusal $(n=2)$, and disease recurrence before SCT could be performed $(n=2)$. Patient characteristics are listed in Table 1. Thirty-six acute diarrhoeal episodes occurred in 22 of $28(79 \%)$ allogeneic SCT recipients, and 12 acute diarrhoeal episodes in 9 of $19(47 \%)$ autologous SCT recipients $(P<0.05)$. Fifteen patients had more than one diarrhoeal episode (two episodes: $n=13$; three episodes: $n=2$ ). Two autologous SCT recipients had diarrhoea before SCT, but no pathogens were isolated. Most of the diarrhoeal episodes occurred during the 3 weeks following SCT in both allogeneic SCT recipients (19 of 36 episodes,
Table 1 Patient characteristics

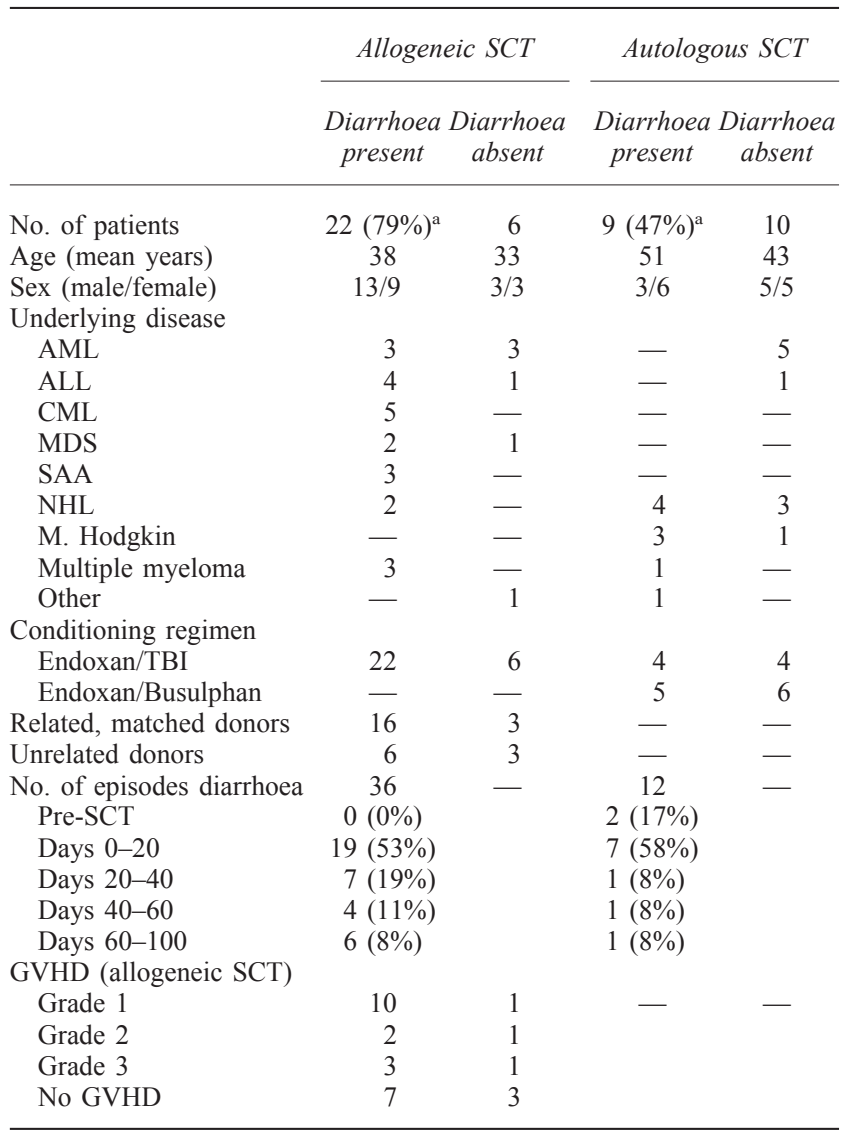

aSignificant difference allogeneic $v s$ autologous SCT recipients $P<0.05$ with $\chi^{2}$ test.

$53 \%$ ) and autologous SCT recipients (seven of 12 episodes, $64 \%$ ). During the period after day 20 post SCT, 47\% (17 of 36) of diarrhoeal episodes occurred in allogeneic SCT recipients, and $25 \%$ (three of 12) of diarrhoeal episodes developed in autologous SCT recipients. Infections were documented in three of $48(6 \%)$ episodes of diarrhoea from three different patients, two of which were due to a toxinproducing $C$. difficile strain, and one was due to cryptosporidium (Tables 2 and 3). No viral pathogens were detected in the stools during diarrhoeal episodes. In the absence of diarrhoea, intestinal pathogens were identified 13 times in 172 stool specimens (Table 4): $C$. difficile, toxin positive $(n=2)$, Salmonella enteritis type $1 \quad(n=1)$, rotavirus $(n=4)$, adenovirus $(n=3)$, echovirus type $9(n=1)$, SRSV $(n=1)$, and cryptosporidium $(n=1)$. No astrovirus was detected and in one stool sample only from an asymptomatic patient could a SRSV be detected with RT-PCR.

In 23 of $36(64 \%)$ episodes of diarrhoea in allogeneic SCT recipients, a clinical diagnosis of GVHD was made. According to established criteria GVHD grades I, II and III were diagnosed in 11, three and four patients, respectively. In two patients, GVHD-induced diarrhoea was established by colonic biopsy. In two other patients, diarrhoeal episodes may have been related to GVHD grades II-III, although no intestinal biopsies were performed. Both these patients also had positive IEA-CMV blood tests at the same 


\begin{tabular}{|c|c|c|c|c|c|c|}
\hline Day of stool specimen & Pathogen & $\begin{array}{c}\text { Frequency of } \\
\text { diarrhoea/24 } h \\
\text { (mean, range) }\end{array}$ & $\begin{array}{l}\text { Duration of } \\
\text { diarrhoea in days } \\
\text { (mean, range) }\end{array}$ & $\begin{array}{l}\text { Neutrophil count } \\
\times 10^{\prime} l(\text { mean, range) }\end{array}$ & $\begin{array}{c}\text { Positive IEA- } \\
\text { CMV }\end{array}$ & GVHD grade (n) \\
\hline Pre-SCT & - & - & - & - & - & - \\
\hline $\begin{array}{l}\text { Days } 0-20 \\
n=19 \text { episodes }\end{array}$ & None & $4.4(2-9)$ & $8.4(2-30)$ & $0.7(<0.1-3.3)$ & 1 & $\begin{array}{l}0(10) \\
1(7) \\
2(2)\end{array}$ \\
\hline $\begin{array}{l}\text { Days } 20-40 \\
n=7 \text { episodes }\end{array}$ & None & $4.8(2-7)$ & $5.6(3-18)$ & $2.3(0.9-3.4)$ & 1 & $\begin{array}{l}0(1) \\
1(4) \\
2(2)\end{array}$ \\
\hline $\begin{array}{l}\text { Days } 40-60 \\
n=4 \text { episodes }\end{array}$ & None & $6(2-10)$ & $3(2-4)$ & $3.4(2.5-4.0)$ & 1 & $\begin{array}{l}0(1) \\
1(1) \\
2(2)\end{array}$ \\
\hline $\begin{array}{l}\text { Days } 60-100 \\
n=6 \text { episodes }\end{array}$ & None & $6.3(2-10)$ & $13.4(2-23)$ & $3.9(2.8-6.1)$ & 1 & $\begin{array}{l}0(1) \\
1(3) \\
2(0) \\
3(2)\end{array}$ \\
\hline
\end{tabular}

Table 3 Diarrhoeal episodes (12) in nine autologous SCT recipients

\begin{tabular}{|c|c|c|c|c|}
\hline Day of stool specimen & Pathogen & $\begin{array}{c}\text { Frequency of } \\
\text { diarrhoea/24 h (mean, } \\
\text { range) }\end{array}$ & $\begin{array}{l}\text { Duration of diarrhoea in } \\
\text { days, (mean, range) }\end{array}$ & $\begin{array}{l}\text { Neutrophil count } \times 10^{9} / l \\
\text { (mean, range) }\end{array}$ \\
\hline $\begin{array}{l}\text { Pre-SCT } \\
n=2 \text { episodes }\end{array}$ & None & $6.5(5-8)$ & $17.5(4-31)$ & $2.4(<0.1-4.7)$ \\
\hline $\begin{array}{l}\text { Days } 0-20 \\
n=7 \text { episodes }\end{array}$ & $\begin{array}{l}\text { C. difficile/toxin positive }(n=1) \\
\text { Cryptosporidium }(n=1)\end{array}$ & $4.7(2-9)$ & $12.6(4-36)$ & $1.9(<0.1-3.7)$ \\
\hline $\begin{array}{l}\text { Days } 20-40 n=1 \text { episode } \\
\text { days } 40-60 \\
n=1 \text { episode }\end{array}$ & C. difficile/toxin positive $(n=1)$ & $\begin{array}{l}\text { NR } \\
\text { NR }\end{array}$ & $\begin{array}{r}6 \\
14\end{array}$ & $\begin{array}{l}9.6 \\
0.1\end{array}$ \\
\hline $\begin{array}{l}\text { Days } 60-100 \\
n=1 \text { episode }\end{array}$ & None & NR & NR & NR \\
\hline
\end{tabular}

$\mathrm{NR}=$ not registered

Table 4 Positive surveillance cultures without diarrhoea in 13 allogeneic and autologous SCT recipients

\begin{tabular}{lcc}
\hline Day of stool specimen & Type of transplant & Pathogen \\
\hline $\begin{array}{l}\text { Pre-SCT } \\
n=2\end{array}$ & Allo & $\begin{array}{c}\text { echovirus type 9 } \\
\text { cryptosporidium }\end{array}$ \\
$\begin{array}{l}\text { Days } 0-20 \\
n=0\end{array}$ & Auto & - \\
$\begin{array}{l}\text { Days 20-40 } \\
n=1\end{array}$ & - & rotavirus \\
Days $40-60$ & Auto & rotavirus \\
$n=3$ & Allo & C. difficile/toxin positive \\
& Auto & adenovirus \\
Days $60-100$ & Auto & adenovirus \\
$n=7$ & Allo & rotavirus \\
& rotavirus \\
& Allo & C. difficile/toxin positive \\
& Adenovirus \\
& Auto & Salmonella enteritis type 1 \\
& Auto & SRSV \\
\hline
\end{tabular}

Allo = allogeneic SCT recipient; Auto = autologous SCT recipient; $\mathrm{SRSV}=$ small round-structured virus. time. There was one patient who had diarrhoea without clinical GVHD, but with a positive IEA-CMV blood test.

\section{Discussion}

Diarrhoeal episodes occur often after stem cell transplantation. In our study, 31 of $47 \mathrm{SCT}$ recipients (66\%) developed one or more episodes of diarrhoea between day 0 and day 100 post transplant. Most diarrhoeal episodes occurred in the period 0-20 days post transplant, probably due to mucosal damage caused by conditioning therapy. Allogeneic SCT recipients developed significantly more diarrhoea than did autologous SCT recipients $(79 \%$ vs $47 \%$ ), especially in the period after day 20 .

Diarrhoea could possibly be attributed to intestinal infection in only three of 48 episodes $(6 \%)$, which is much lower than the incidence of $13 \%$ to $40 \%$ reported by others..$^{1-3,5}$ No pathogens were isolated in stool specimens of 22 allogeneic SCT recipients with acute diarrhoea. In three of nine autologous transplant patients, diarrhoeal illness could be attributed to microbial pathogens (two toxin producing $C$. difficile strains and one cryptosporidium). No viral pathogens were found in cases of diarrhoea.

C. difficile has been reported as being the most common 
bacterial cause of diarrhoea in stem cell transplant patients, affecting $14 \%$ to $30 \%$ of them. ${ }^{1-3}$ In our study, $C$. difficile infection was the most frequently isolated pathogen in both surveillance cultures (six times) and in cases of diarrhoea (five times). However, $C$. difficile toxin was detected in only four patients in faeces. C. difficile is frequently transmitted among hospitalised patients, but we did not find clustering of diarrhoeal episodes with $C$. difficile. Six patients acquired this organism during hospitalisation (in two faecal samples toxin was present), and five patients in the outpatient environment (with two toxin-positive faecal samples). No association was found with the use of specific antibiotics.

During surveillance cultures only one asymptomatic patient had a stool specimen positive for a bacterial pathogen, ie Salmonella enteritis type 1.

One patient had a cryptosporidium infection. This patient developed diarrhoea in the first weeks after SCT. Only one stool test was positive for cryptosporidium, and follow-up tests remained negative. We found one carrier of cryptosporidium prior to SCT. This patient developed diarrhoea twice in the post-transplant period, but no cryptosporidium could be detected during diarrhoeal episodes. Cryptosporidosis has been associated with diarrhoea and asymptomatic intestinal carriage. ${ }^{13,14}$ Intestinal infection may be related to activation of latent cryptosporidial infection. ${ }^{15}$ In one prospective study, cryptosporidium was detected in the stools of $14 \%$ of haematologic cancer patients with diarrhoea, and in $1.4 \%$ of asymptomatic patients, ${ }^{16}$ suggesting an aetiological role. However, other authors have not reported such a high incidence of cryptosporidial infections in transplant patients. ${ }^{2,17}$ No episodes of diarrhoea were associated with detection of viruses. This outcome is of note since other studies reported an incidence of viral enteritis in SCT recipients from $8 \%$ to $28 \%{ }^{1,2,5}$ Seasonal influences were taken into account since our study period covered 12 months. Adenovirus and rotavirus were the most reported viral pathogens in cases of diarrhoea in SCT recipients. Conventional adenoviral serotypes do not frequently cause gastro-enteritis, but serotypes 40 and 41 are categorised as enteric adenoviruses. ${ }^{18}$ Without serotyping it is difficult to prove that adenoviruses produce gastro-enteritis because of the prolonged period of asymptomatic faecal shedding after respiratory tract infection with traditional adenoviruses. ${ }^{19}$ We found a positive ELISA and/or culture for adenovirus during surveillance cultures of faeces in three asymptomatic SCT recipients. After serotyping, one of the patients was positive for serotype 41. Intestinal infection with rotavirus is normally uncommon in adults, but chronic infection with this pathogen has been described in immunocompromised patients. ${ }^{20}$ In northern Europe rotavirus infections occur seasonally, primarily during the cooler winter months. Rotaviral disease in SCT recipients can occur in epidemic clusters. ${ }^{1,5} \mathrm{We}$ found a positive ELISA for rotavirus of stool specimens in four SCT recipients without diarrhoeal episodes. All patients with faecal shedding of adenovirus and rotavirus were treated as outpatients, and were probably infected by the environment. The time between SCT and first virus isolation in these patients was 69 days (range 40-101 days) after SCT. In addition, one patient was an asymptomatic carrier of echovirus type 9 before transplantation, and one SCT recipient was a carrier of a SRSV. Small round-structured viruses cause approximately $80 \%$ of the outbreaks of gastro-enteritis that occur in institutions such as nursing homes and hospitals in The Netherlands and other countries. ${ }^{21}$ The virus is spread by the faecal-oral route, with an incubation period of 12 to $48 \mathrm{~h}$. Astrovirus was not detected in stool specimens of our study population. Astroviral disease is frequent in children and similar to rotaviral illness, but less severe. Faecal shedding of the virus in asymptomatic children has been reported and nosocomial transmission can occur. ${ }^{22}$

Some studies have described an association between moderate to severe GVHD and the occurrence of viral infection in allogeneic SCT recipients. ${ }^{1,5} \mathrm{We}$ failed to reproduce this relationship in our study, due to low incidence of virus infection as well as a low incidence of GVHD ( $\geqslant$ grade II; 32\%), since all patients received T celldepleted donor marrow.

The low incidence of infectious gastro-enteritis in our studied SCT population may be due to several factors. Prophylaxis with oral ciprofloxacin $500 \mathrm{mg}$ twice daily during severe neutropenia largely stops diarrhoeal illness caused by endogenous micro-organisms as well as enteric pathogens such as salmonella, campylobacter and toxinproducing bacteria. Pre-emptive therapy with ganciclovir in the event of a positive IEA-CMV blood test can prevent diarrhoeal illness caused by cytomegalovirus. Careful hygiene measures during hospitalisation may also contribute to the low incidence of gastrointestinal infection, particularly of viral origin. More than $50 \%$ of the diarrhoeal episodes occurred during the first 3 weeks after SCT, of which only two diarrhoeal episodes could be related to a pathogen isolated in the stool. Mucosal damage due to conditioning therapy, the use of broad-spectrum antibiotics and other drugs may be explanations for occurrence of diarrhoea in the early phase after SCT. In the period after day 20 post transplant, diarrhoea could be associated with an intestinal infection in only one patient. GVHD was implicated in four episodes of diarrhoea after day 20 post transplant in allogeneic SCT recipients, and cytomegalovirus was temporally associated with diarrhoeal episodes in three patients during this period. Enteric viruses did not cause serious intestinal infections, although shedding of enteric viruses in the faeces of asymptomatic patients could be found during surveillance of stool specimens. Thus, isolation of virus in a stool specimen, even in cases of diarrhoea, may not only be related to intestinal infection, but may also be a result of viral shedding. Previous reports have not always emphasised this point. We did not seek other groups of viruses known to cause diarrhoea, such as coronavirus, non-group A rotavirus and picobirnavirus, so we cannot stipulate that these viruses were not responsible for diarrhoeal episodes in this study. We conclude that, in accordance with our results, it is not necessary to routinely perform tests to detect viral pathogens in SCT recipients with diarrhoea, unless an endemic origin is suspected.

\section{References}

1 Yolken RH, Bishop CA, Townsend TR et al. Infectious gastroenteritis in bone-marrow-transplant recipients. New Engl J Med 1982; 306: 1009-1012. 
2 Cox GJ, Matsui SM, Lo RS et al. Aetiology and outcome of diarrhoea after marrow transplantation: a prospective study. Gastroenterology 1994; 107: 1398-1407.

3 Yuen KY, Woo PC, Liang RH et al. Clinical significance of alimentary tract microbes in stem cell transplant recipients. Diagn Microbiol Infect Dis 1998; 30: 75-81.

4 Goodgame RW. Gastrointestinal cytomegalovirus disease. Ann Intern Med 1993; 119: 924-935.

5 Troussard X, Bauduer F, Gallet E et al. Virus recovery from stools of patients undergoing stem cell transplantation. Bone Marrow Transplant 1993; 12: 573-576.

6 Kanfer EJ, Abrahamson G, Taylor J et al. Severe rotavirusassociated diarrhoea following stem cell transplantation: treatment with oral immunoglobin. Bone Marrow Transplant 1994; 14: 651-652.

7 Shields AF, Hackman RC, Fife $\mathrm{KH}$ et al. Adenovirus infections in patients undergoing bone-marrow transplantation. New Engl J Med 1985; 312: 529-533.

8 Verdonck LF, Dekker AW, Rozenberg-Arska M, van de Hoek M. A risk-adapted approach with a short course of ganciclovir to prevent cytomegalovirus (CMV) pneumonia in CMV-seropositive recipients of allogeneic stem cell transplants. Clin Infect Dis 1997; 24: 901-907.

9 Thomas ED, Storb R, Clift RA et al. Stem cell transplantation (second of two parts). New Engl J Med 1975; 292: 895-902.

10 Jong de JC, Bijlsma K, Wermenbol AG et al. Detecting, typing, and subtyping of enteric adenoviruses 40 and 41 from fecal samples and observation of changing incidences of infections with these types and subtypes. J Clin Microbiol 1993; 31: $1562-1569$.

11 Vinjé J, Koopmans MPG. Molecular detection and epidemiology of small round structure viruses in outbreaks of gastroenteritis in the Netherlands. J Infect Dis 1996; 174: 610-615.

12 Noel JS, Lee TW, Kurtz JB et al. Typing of human astrovirus from clinical isolates by enzyme immunoassay and nucleotide

13 Wolfson JS, Richter JM, Waldron MA et al. Cryptosporidiosis in immunocompetent patients. New Engl J Med 1985; 312: 1278-1281.

14 Zar F, Geiseler J, Brown VA. Asymptomatic carriage of cryptosporidium in the stool of a patient with acquired immunodeficiency syndrome (letter). J Infect Dis 1985; 151: 195.

15 Holley HP Jr, Thiers BH. Cryptosporidiosis in a patient receiving immunosuppressive therapy. Possible activation of latent infection. Dis Dig Sci 1986; 31: 1004-1007.

16 Gentile G, Venditti M, Micozzi A et al. Cryptosporidiosis in patients with hematologic malignancies. Rev Infect Dis 1991; 13: 842-846.

17 Collier AC, Miller RA, Meyers JD. Cryptosporidiosis after marrow transplantation: person to person transmission and treatment with spiramycin. Ann Intern Med 1984; 101: 205206.

18 Blacklow NR, Greenberg HB. Viral gastroenteritis. New Engl J Med 1991; 325: 252-264.

19 Fox JP, Hall CE, Cooney MK. The Seattle virus watch. VII. Observations on adenovirus infections. Am J Epidemiol 1977; 105: 362-386.

20 Peigue-Lafeuille $\mathrm{H}$, Henquell $\mathrm{C}$, Chambon $\mathrm{M}$ et al. Nosocomial rotavirus infections in adult renal transplant recipients. J Hosp Infect 1991; 18: 67-70.

21 Vinjé J, Altena SA, Koopmans MPG. The incidence and genetic variability of small round-structured viruses in outbreaks of gastroenteritis in the Netherlands. J Infect Dis 1997; 176: 1374-1378.

22 Herrman JE, Perron-Henry DM, Blacklow BR. Antigen detection with monoclonal antibodies for the diagnosis of adenovirus gastroenteritis. J Infect Dis 1987; 155: 1167-1171. 